\title{
A Sun Path Observation System Based on Augment Reality and Mobile Learning
}

\author{
Wernhuar Tarng $\mathbb{D}^{1},{ }^{1}$ Kuo-Liang Ou $\mathbb{D}^{1},{ }^{1}$ Yun-Chen Lu, ${ }^{1}$ Yi-Syuan Shih, ${ }^{2}$ and Hsin-Hun Liou ${ }^{2}$ \\ ${ }^{1}$ Institute of Learning Sciences and Technologies, National Tsing Hua University, Hsinchu, Taiwan \\ ${ }^{2}$ Department of Computer Science and Information Engineering, National Central University, Taoyuan, Taiwan
}

Correspondence should be addressed to Kuo-Liang Ou; klou@mail.nd.nthu.edu.tw

Received 19 October 2017; Revised 26 January 2018; Accepted 8 February 2018; Published 29 March 2018

Academic Editor: Jesus Fontecha

Copyright (c) 2018 Wernhuar Tarng et al. This is an open access article distributed under the Creative Commons Attribution License, which permits unrestricted use, distribution, and reproduction in any medium, provided the original work is properly cited.

\begin{abstract}
This study uses the augmented reality technology and sensor functions of GPS, electronic compass, and three-axis accelerometer on mobile devices to develop a Sun path observation system for applications in astronomy education. The orientation and elevation of the Sun can be calculated by the system according to the user's location and local time to simulate the Sun path. When holding the mobile device toward the sky, the screen will show the virtual Sun at the same position as that of the real Sun. The user can record the Sun path and the data of observation date, time, longitude, and latitude using the celestial hemisphere and the pole shadow on the system. By setting different observation times and locations, it can be seen that the Sun path changes with seasons and latitudes. The system provides contextual awareness of the Sun path concepts, and it can convert the observation data into organized and meaningful astronomical knowledge to enable combination of situated learning with spatial cognition. The system can solve the problem of being not able to record the Sun path due to a bad weather or topographical restrictions, and therefore it is helpful for elementary students when conducting observations. A teaching experiment has been conducted to analyze the learning achievement of students after using the system, and the results show that it is more effective than traditional teaching aids. The questionnaire results also reveal that the system is easy to operate and useful in recording the Sun path data. Therefore, it is an effective tool for astronomy education in elementary schools.
\end{abstract}

\section{Introduction}

Astronomy is the scientific study of celestial objects such as stars, planets, and galaxies as well as the phenomena that originate outside the Earth's atmosphere. It is an important field of study investigating the problems of immediate concern to human beings, for example, the Sun, Moon, stars, seasonal changes, day and night, lunar phase, and rising and setting of stars. These changes are closely related to our daily life. The astronomical observation is an important topic of natural science in elementary schools [1]. Students can think about the relative motion between celestial bodies and their interaction by observing the changes of astronomical phenomena and investigate the problems using scientific methods to obtain the answers. Consequently, it can enhance their critical-thinking and problem-solving abilities [2].
There are several learning units about astronomy education in K-12 Science Education Curriculum [3]. In the "Lunar phase" unit (the fourth grade of elementary school), students may find out that the change of lunar phase is regular by observing moonrise and moonset for a month. In the "Sun and four seasons" unit (the fifth grade of elementary school) and the "Sun, Earth, and Moon" unit (the third grade of junior high school), students may understand that the change of seasons, day and night, lunar phase, solar eclipse, and lunar eclipse are caused by the relative motion of celestial bodies, that is the Sun, Earth, and Moon, by observing sunrise, sunset, moonrise, and moonset and operating the celestial model. In the "Beautiful night sky" unit (the fifth grade of elementary school), students may conduct a long-term observation to discover that the change of star positions in the night sky is caused by the rotation of Earth 
and its revolution around the Sun. It may help them establish the concepts of time and space.

The Sun is closely related with human life because it provides the light and energy for all organisms on the Earth. The Earth's axis is tilted at $23.5^{\circ}$, making the Northern Hemisphere point at the Sun more directly half the year, and the Southern Hemisphere does the same the other half. In the Northern Hemisphere, days reach their maximum (minimum) lengths at the summer (winter) solstice when the upper half of the planet faces directly toward (away from) the Sun. In the spring and fall, days and nights are roughly equal at the two equinoxes. The change of day and night affects our lifestyle and daily routine, the variation of day (night) time impacts animal and plant adaptations and behaviors, and the change of seasons influences farming and harvest. Therefore, observing the Sun to know its impacts on human life is important in science education.

Due to the Earth's rotation, the position of the Sun moves in the sky from time to time. In traditional teaching activities of the Sun path observation, the students are required to record the pole shadow and the Sun's position using the teaching aids of celestial hemisphere, compass, and protractor for measuring the Sun orientation and elevation. The learning objective is to find out the change of the Sun's position in the sky. The teacher may also use pictures and animations to show the Earth's revolution around the Sun and the tilted angle of its rotational axis for students to understand the regular change of the Sun path in four seasons and the relationship between the latitude of the observer's location and elevation of the Sun.

The observation of Sun path is often restricted by time, weather, and topographical conditions. If the observational activity is scheduled at noon, it may be affected by the hot weather for which can result in heatstroke when a person has been exposed to a hot environment for an extended period of time. The activity may also be cancelled due to typhoons or rainfall for several days during summer and autumn. Besides, it is impossible to measure the pole shadow in cloudy days or if the Sun is obstructed by tall buildings. To compare the Sun paths in different seasons, the observation has to be continued for a whole year. Some students have no perseverance to complete the task, so they gradually lose learning interest and confidence.

In addition to the efforts required in observing and recording the Sun path, the astronomical concepts have to be developed by induction and imagination according to the recorded data, which is difficult especially when the data are not complete. For example, most students do not have the chance to conduct observations at different latitudes or the patience to continue recording for a whole year. In order to understand how the Sun path changes in different seasons or at different latitudes, the students have to imagine themselves standing at a certain latitude on the Earth and think about the Sun's position as the Earth is rotating by itself. Therefore, they may have misconceptions about the relative motion of celestial bodies when studying complex astronomical phenomena [4-6]. All these factors affect the development of astronomical concepts.
With the innovation of information and communication technology (ICT), mobile devices, such as personal digital assistant (PDA), smart phone, and tablet PC, are more powerful and have been applied widely in different fields of learning. As a result, learning activities are no longer limited to classroom teaching, and they can be conducted by using any device at anytime from anywhere to achieve the so-called ubiquitous learning [7, 8]. As the smart phone and tablet PC become more and more popular, many virtual reality (VR) and augmented reality (AR) apps have been developed on mobile devices for entertainment and educational applications. VR replaces the real world with a simulated one whereas AR enhances one's current perception of reality through superimposing VR objects onto real environments. AR emphasizes the combination of contexts in the real world with virtual or real situations to intensify its interaction with users. AR can integrate a real environment with virtual objects to enhance the comprehension of environmental context and the sense of reality in a more interactive way. Recent research has shown that applications of AR in learning can improve knowledge construction and engage learners in high-flow experience levels [9-11]. Therefore, AR can be used as an effective tool to promote science learning [12-15].

Many researchers believe that VR and AR technologies are becoming mature and will be broadly used in industries such as architecture and construction as well as science, technology, and engineering education within the next 10 years. The present time can be a turning point of the applications of VR and AR due to the increasing development of hardware and software. The applications of AR technology in industrial training and science education can enhance one's perception of reality through superimposing VR objects onto real environments to bridge the gap between the virtual and physical worlds. According to the review of augmented reality learning experiences (ARLEs) conducted by Drljevic, Wong, and Boticki [16], some ARLEs support one or more of active, constructive, authentic, intentional, and cooperative learning, but only two studies describe ARLEs that offer effective support for a teacher to guide the activities.

Recently, the AR technology has been widely used in creating learning experiences for educational settings in elementary and high schools. Santos et al. [17] conducted a review of AR applications intended to complement traditional curriculum materials, and their research results showed that ARLEs achieved a widely variable effect on student performance from a small negative effect to a large positive effect. A qualitative analysis was performed on the design aspects for ARLEs, including display hardware, software libraries, content authoring solutions, and evaluation techniques to support their finding that AR incurs three inherent advantages: real world annotation, contextual visualization, and vision-haptic visualization. The advantages were illustrated through the exemplifying prototypes supported by multimedia learning theory, experiential learning theory, and animate vision theory to inform the design of future ARLEs.

In our previous study [18], the AR technology has been applied to develop a lunar-phase observation system. The system enables the user to record the lunar phase, including its azimuth/elevation angles and the observation date/time. 
In addition, the system can shorten the learning process by setting different dates and times for observation, so it can solve the problem of being unable to observe and record lunar phases due to bad weather or the Moon appearing late in the night. The experiment results showed that it is effective in learning the lunar concepts, and the questionnaire results revealed that students considered the system easy to operate and useful in locating the Moon and recording the lunar data.

In this study, the AR technology and sensor functions of GPS, electronic compass, and three-axis accelerometer on mobile devices are combined to develop a Sun path observation system for educational applications in elementary schools. A celestial model is developed to simulate the Earth's rotation and its revolution around the Sun. The orientation and elevation of the Sun can be calculated by this model according to the location (latitude and longitude) and local time of the user to simulate the Sun path in the sky. When holding the mobile device toward the Sun, the screen will show the virtual Sun in the same direction as that of the real Sun. The user can record the Sun path as well as the observation data such as the date, time, orientation, and elevation using the celestial hemisphere and pole shadow on the system and set different observation times and locations to understand that the Sun path changes with seasons and latitudes.

This study differs from the previous study because the celestial objects and the tools used for observation are different. The relative movement of the Sun to the Earth and the calculation of its path are different from those of the lunarphase observation system since the Moon is revolving around the Earth which is also revolving around the Sun at the same time. When observing the Moon, the orientation and elevation are measured by the sensors on the mobile device and recorded as the data for calculating its position in the sky. To display the Sun path, the azimuth/elevation angles have to be mapped to the surface of the three-dimensional celestial hemisphere and match with the data calculated by the length and orientation of the pole shadow. Even with the same AR technology and the sensors on mobile devices, the coordinate systems of the targets for observation are different, and they have to be calculated according to the periods of the Earth's rotation and revolution.

In addition, the current study has to implement a celestial hemisphere and a pole stick for observing and recording the Sun path. The Sun path observation system enables the user to look from inside and outside of the celestial hemisphere to observe the Sun and its path by a simple motion-sensing operation. Also, the Sun paths of different seasons or different latitudes can be displayed together for comparison to help students understand that the Sun path changes with the seasons and latitudes. Finally, the function of autorecording is implemented to reduce the observation and recording time.

\section{Research Method}

Astronomy is an important topic in the curriculums of science education in elementary and high schools. However, students are often confused by the complicated spatial concepts involved in the relative motion of celestial bodies and therefore have misconceptions after learning. Due to the limited class time, some teachers can only demonstrate how to use the celestial hemisphere, compass, and protractor to record the Sun path and then require students to conduct observation by themselves after class. Without proper and timely supports of effective instructional scaffolding, students may have difficulties in obtaining the necessary experiences and knowledge for developing correct astronomical concepts. As a result, they may use incorrect methods to conduct observations and eventually lose their confidence and learning interest.

In practice, the teaching activities of astronomical observation in the curriculums of science education are designed based on the theory of "learning by doing" [19]. Therefore, it is better to encourage students to conduct outdoor observation and practical operation using the teaching aids, simulation models, and computer animation in real or virtual environments. To achieve the learning goals, the teacher can use some instructional strategies or assistant tools to enhance students' learning effectiveness. The objective is for the students to develop experimentation skills and conceptual knowledge by hands-on experiences.

Many students believe that summer is hotter because the distance between the Sun and the Earth is shorter. In fact, the Sun is farther from the Earth in the summer of the Northern Hemisphere, which is the winter of the Southern Hemisphere. Scientists have discovered that the distance between the Sun and the Earth is not the cause of seasonal change while it is caused by the revolution of the Earth around the Sun and the inclination of the Earth's axis. If the axis were perpendicular to the orbital plane, there would be no seasonal changes. However, the Earth's axis is tilted at $23.5^{\circ}$, causing the Earth's surface exposed to the direct sunlight to change from season to season. At the summer solstice (the summer of the Northern Hemisphere), Tropic of Cancer is exposed to the direct sunlight; at the winter solstice (the winter of the Northern Hemisphere), Tropic of Capricorn is exposed to the direct sunlight; and at the vernal equinox and the autumnal equinox (the spring and autumn of the Northern Hemisphere), the equator is exposed to the direct sunlight (Figure 1).

The Sun's position in the sky changes with time due to the Earth's rotation, and the Sun path varies with the Earth's position in its orbit as well as the observer's latitude on the Earth, which is caused by the inclination of the Earth' axis. At the summer solstice, the Sun is more northward in the sky in regions with higher latitudes in the Northern Hemisphere. In the Arctic Circle, the Sun path is always above the horizon in summer, and there are 24 hours of daylight everywhere north of $66.5^{\circ} \mathrm{N}$ latitude, dubbed "Arctic white nights." The Sun path also varies with seasons because the Earth's position keeps changing on its orbital plane. For example, Tropic of Cancer cuts across Taiwan at Chiayi, where the Sun is northward at the summer solstice. It is above the head at noon, and thus the shadow of a person can hardly be seen. At the winter solstice, the Sun's elevation is about $45^{\circ}$ at noon, so the shadow is about the same length as one's height.

Because one cannot look at the Sun directly due to its dazzling light and the fact that the Sun's orientation and elevation are not marked by any signs in the sky, the four 


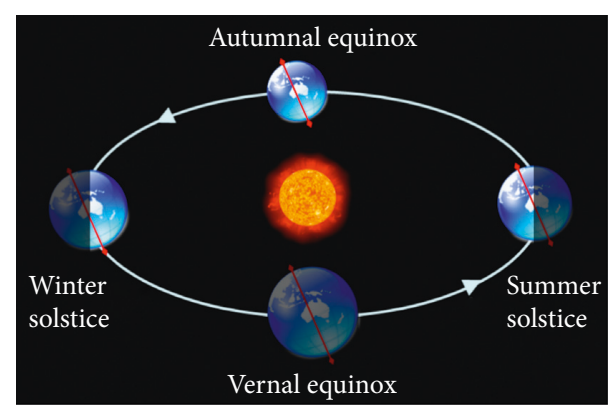

Figure 1: Seasonal changes by the inclination of the Earth's axis.

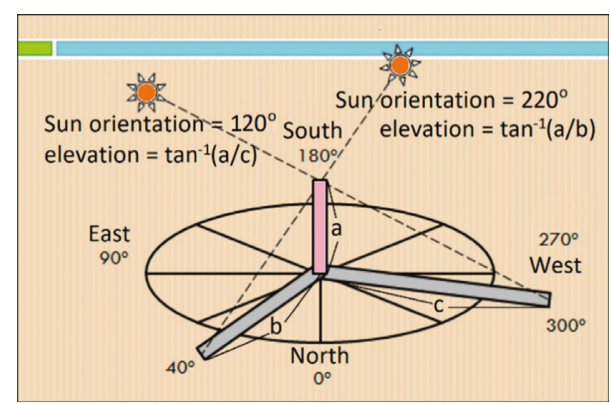

FIgURE 2: Measuring the Sun's orientation and elevation with the pole shadow.

seasons and 24 solar terms in ancient China were determined by setting up a sundial for measuring its shadow to tell the seasonal changes. In teaching the Sun path observation, the teachers often simulate the Sun with a flashlight for the students to know that the shadow of an object is in the direction opposite to the light source and the Sun's elevation can be calculated by the length of pole shadow using trigonometric functions (Figure 2). For example, the orientation of the Sun is $120^{\circ}$ if the orientation of the pole shadow is $300^{\circ}$, and its elevation can be calculated by $\tan ^{-1}(a / c)$. Finally, the measured orientation and elevation are marked on the celestial hemisphere to form the Sun path in a day. The observation results can also be used to induce the regular change of the Sun's position on a daily basis.

This study is motivated by the requirements of teaching the Sun path observation in the K-12 Science Education Curriculum in Taiwan. A celestial model containing the Sun and Earth is developed using the AR technology to simulate the Earth's rotation and its revolution around the Sun. A virtual celestial hemisphere with a pole at its center for measuring the shadow is placed on the Earth model for students to record the Sun's position in the sky. The students can observe and record the Sun's orientation and elevation as well as the related data such as the observation date, time, longitude, and latitude to understand that the Sun path changes with seasons and latitudes. They can also calculate the Sun's azimuth/elevation angles by measuring the orientation and length of the pole shadow for verifying correctness of the Sun's position.

To break through the limitations of observation time, location/ and weather conditions, this study aims at satisfying the teaching requirements by developing a Sun path

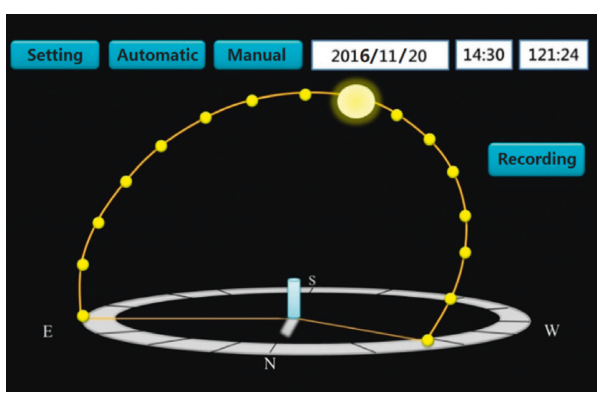

FIgURE 3: Proposed model of the Sun path observation system.

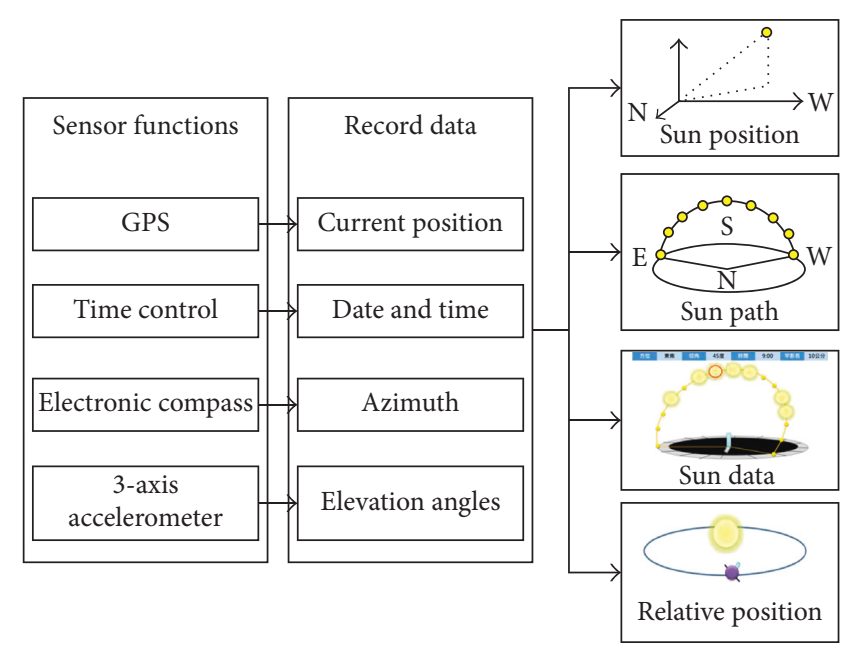

Figure 4: Main modules of the Sun path observation system.

observation system for applications in science education in elementary schools. A preliminary study has been conducted on the research problems of (1) how to obtain the date, time, longitude, and latitude on the mobile device; (2) how to obtain the orientation and elevation of the mobile device with its sensors; (3) how to calculate the Sun path according to the Sun's position in its orbit as well as the observation date, time, longitude, and latitude; (4) how to develop a motion-sensing interface for the user to observe the Sun by holding the mobile device toward its direction; and (5) how to record data, generate the Sun path, and determine the relations between the Sun path and the Earth's position in its orbit as well as the user's latitude. The main modules of the Sun path observation system developed in this study include (1) a virtual Sun to simulate the real Sun's position, (2) a pole shadow for calculating the Sun orientation and elevation, and (3) a celestial hemisphere for recording the Sun path (Figure 3).

\section{System Design and Operation}

The operating procedure of the Sun path observation system is (1) obtaining the longitude and latitude coordinates from the GPS system and (2) calculating the orientation and elevation of the mobile device using the electronic compass and the three-axis accelerometer. The above data together 


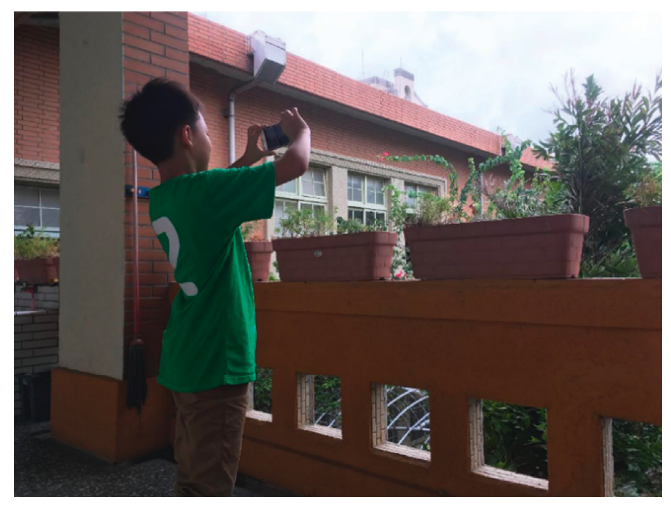

(a)

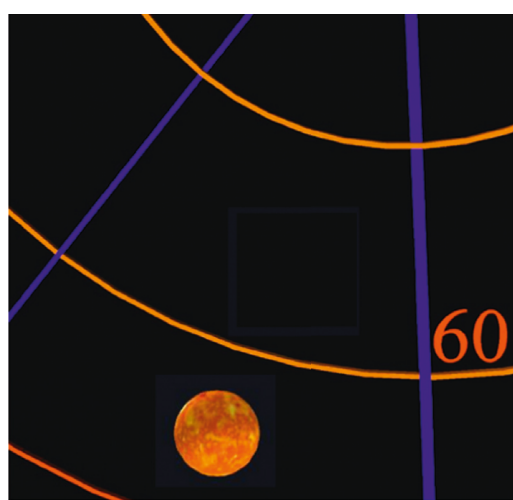

(b)

Figure 5: Holding the mobile device toward the Sun in the sky.

with the system date and time are input to the celestial model of the Earth's revolution around the Sun for (3) calculating the position of the virtual Sun in the sky. The system provides a motion-sensing interface for the user to conduct the Sun observation by holding the mobile device toward the sky to locate the Sun's position. The recorded data can be used for (4) displaying the Sun path on the hemisphere model and the Earth's position in its orbit.

The main modules of the Sun path observation system include the "GPS," "time control," "electronic compass," "three-axis accelerometer," "Sun position," "Sun path," "Sun data," "revolution model," "celestial hemisphere," and the modules for setting date, time, location, and operating speed (Figure 4).

The major functions of the Sun path observation system include (1) Sun observation, (2) recording the Sun path data, (3) setting observation date, time, and location, (4) displaying the Sun path, and (5) displaying the Earth's position in its orbit, and their user interface are described as follows.

3.1. Sun Observation. After starting the Sun path observation system, the mobile device obtains the longitude and latitude coordinates from the GPS system and measures its orientation and elevation using the electronic compass and the three-axis accelerometer. To facilitate the Sun observation and displaying of the Sun data, the background color of the user interface is set to black. When the elevation of the mobile device is within $90^{\circ}$ of the horizontal plane, the user can see a celestial hemisphere on the screen with a pole shadow located at its center. If the elevation of the mobile device is more than $90^{\circ}$, the system simulates the user looking at the sky from the center of the celestial hemisphere to observe the Sun (Figure 5). By holding the mobile device toward the Sun in the sky, the user can see the virtual Sun in the same direction as that of the real Sun. In addition, Sun's orientation and elevation, current date and time, longitude and latitude are displayed on the screen. The user can record the data by simply pressing the "Recording" button.

3.2. Recording the Sun Path Data. When the user presses the "Recording" button, the observation data are stored as the

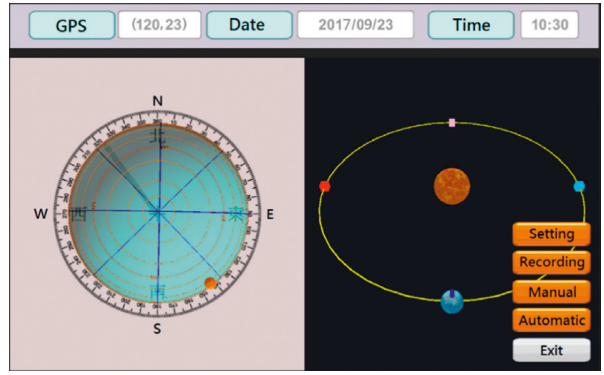

Figure 6: Recording Sun's position on the celestial hemisphere.

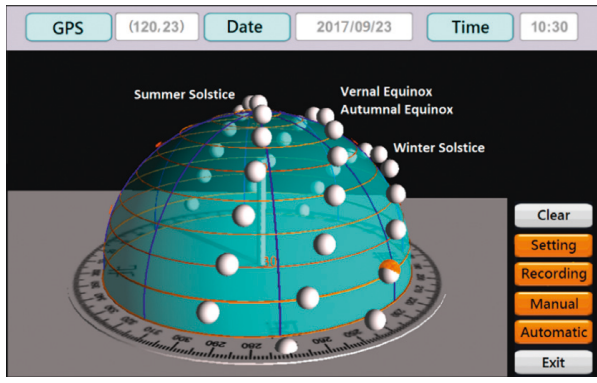

FIgURE 7: Displaying the Sun paths in different seasons at Tropic of Cancer.

environment variables which can be retrieved at any time for displaying the Sun path. Several sets of data, for example, in different seasons or at different latitudes, can be combined together and converted into the Sun paths on the celestial hemisphere for comparison. The user may set the recording mode as "Manual" to record the data one at a time or "Automatic" to record the data once per hour for the whole day. The operating speed may also be adjusted so that the user can obtain the Sun path in a short time (Figure 6).

3.3. Setting Observation Date, Time, and Location. The Sun path observation system provides the function of setting observation date, time, and location. The user can press the "Setting" button to adjust the observation date and time. For 


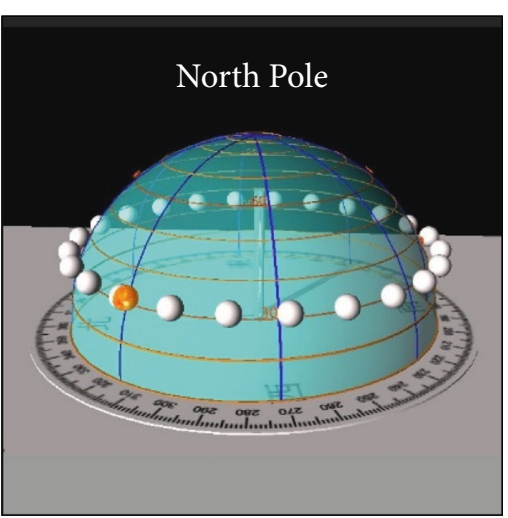

(a)

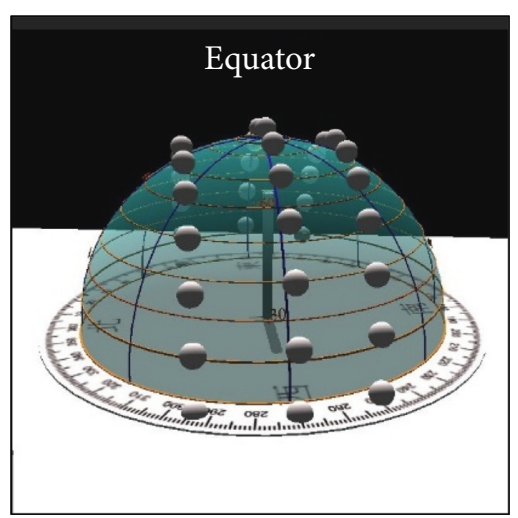

(b)

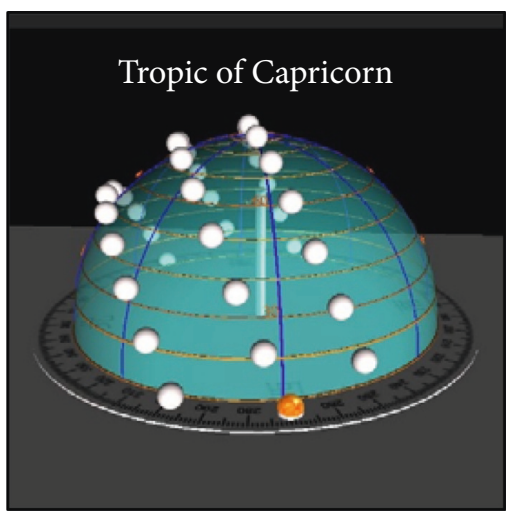

(c)

FIgURE 8: Comparing the difference of the Sun paths at different latitudes.

simplicity, the system provides the options of vernal equinox, summer solstice, autumnal equinox, and winter solstice for the teaching purpose. After setting the observation date, the user can see that the the Earth's position changes accordingly in its orbit and so does the Sun's position in the sky. The system date/time can be reset by pressing the "Now" button. The user may also change the observation location by setting its latitude and longitude coordinates. The system provides several representative coordinates, such as "Tropic of Cancer," "Tropic of Capricorn," "Equator," "North Pole," "South Pole," and the "Here" button for returning to the current location. The user may understand the relation between the Sun path and the latitude by setting different observation locations.

3.4. Displaying the Sun Path. The user can press the "Management" button to select the observation data for displaying the Sun path. The system will group the observation data recorded on the same day at the same location into a set of data and display Sun's positions on the celestial hemisphere according to the time sequence so that the user may see the Sun path during the observation day to achieve the teaching objectives of (1) observing sunrise and sunset by recording Sun's position in the sky, (2) understanding that Sun's position varies with time, and (3) knowing how to draw the Sun path on the celestial hemisphere. Also, the user may combine several sets of data (Figure 7) to compare the difference of the Sun paths at different latitudes (e.g., Tropic of Cancer, Tropic of Capricorn, Equator, North Pole, and South Pole) or in different seasons (e.g., the vernal equinox, the summer solstice, the autumnal equinox, and the winter solstice).

3.5. Displaying the Earth's Position in Its Orbit. In addition to the Sun path in the sky, the system can also display the Earth's revolution model to show the relation between the Earth's position in its orbit and the change of Sun path. The teacher may explain to students that the period of the Earth's revolution is one year, and the regions exposed to the direct sunlight change from season to season due to the inclination of the Earth's axis. After operating the Sun path observation system, it is easier for students to understand that at the summer solstice, the Tropic of Cancer is exposed to the direct sunlight; at the vernal equinox and the autumnal equinox, the equator is exposed to the direct sunlight; and at the winter solstice, the Tropic of Capricorn is exposed to the direct sunlight (Figure 8). Using the system, the students can easily understand how the Earth rotates by itself at a tilted angle and revolves around the Sun along its orbit, and all these cause the Sun path to change with latitudes and seasons.

3.6. Longitudinal Effect on the Sun Path. Sun's position in the sky changes with time due to the Earth's rotation. To calculate the rotation angle of the Earth model per unit time, it is required to know the time for the Earth to rotate once $\left(360^{\circ}\right)$. Traditionally, a solar day (24 hours) is defined as the time between two successive transits of the Sun across the meridian. However, the angle that the Earth rotates for a solar day is slightly greater than $360^{\circ}$ because the Earth is also revolving around the Sun during its rotation. The time for the Earth to rotate $360^{\circ}$ (a sidereal day) can be calculated as follows. In each solar day, as the Earth makes a $360^{\circ}$ revolution around the Sun in a year (about 365 days), it must turn about an additional degree to see the Sun on meridian. Therefore, it takes about $24 \times 60 / 361=4$ minutes for the Earth to rotate one degree, and therefore a sidereal day is only about 23 hours and 56 minutes. In the celestial model, the sidereal day is used to calculate the time required for the Earth to rotate $360^{\circ}$ to obtain the accurate simulation results.

The Sun path varies with the Earth's position in its orbit as well as the observer's latitude on the Earth, and it is caused by the inclination of the Earth' axis. However, the Sun path at the same latitude remains the same even if the longitude changes. It can be seen in Figure 9 that the Sun paths are not changed if the longitude is moved from $120^{\circ}$ to $210^{\circ}$ while the latitude remains the same $\left(23^{\circ}\right)$. It is caused by the fact that the Earth surface at the same latitude exposed to the direct sunlight (at noon) always turns to the same position at about the same time. There are $360^{\circ}$ of longitude and 24 hours in a day, so every $15^{\circ}$ of longitude equals one time zone (an hour). A time zone is a region on the Earth with a uniform 


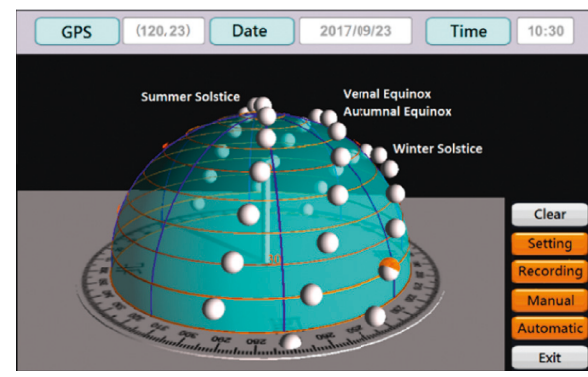

(a)

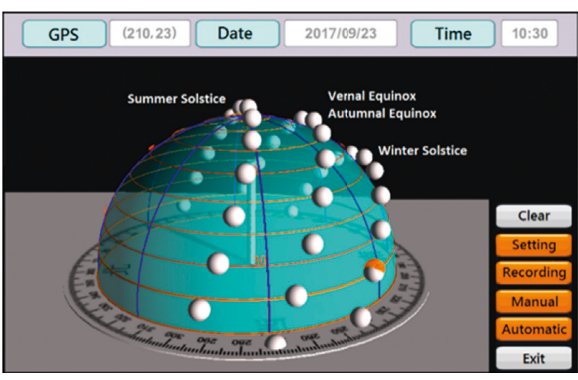

(b)

Figure 9: Comparing the difference of the Sun paths at different longitudes.

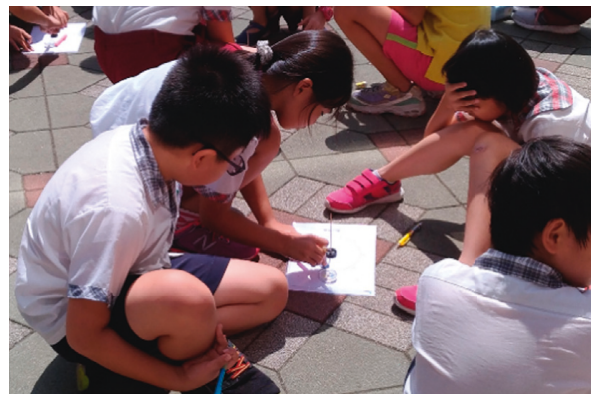

(a)

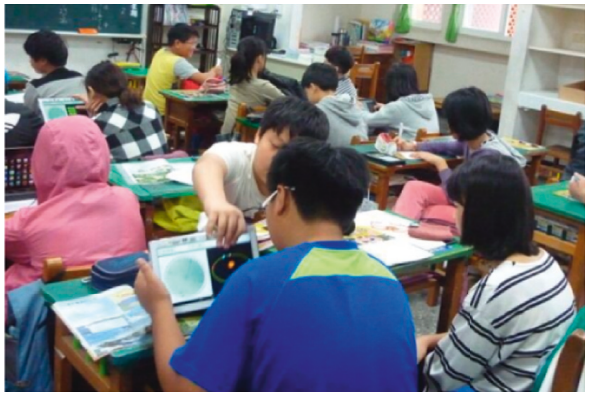

(b)

Figure 10: Conducting the teaching experiment. (a) control group; (b) experimental group.

TABLE 1: Variables of the teaching experiment.

\begin{tabular}{lcc}
\hline & $\begin{array}{c}\text { Control group } \\
\text { Experimental group }\end{array}$ & $\begin{array}{c}\text { Traditional teaching aids } \\
\text { The Sun path observation system }\end{array}$ \\
\hline $\begin{array}{l}\text { Covariance } \\
\text { Dependent variable }\end{array}$ & $\begin{array}{c}\text { Achievement test (pretest) } \\
\text { Control variable }\end{array}$ & Achievement test (posttest) \\
\hline
\end{tabular}

standard time for legal, commercial, and social purposes. Because the local time data obtained within a time zone are the same, the Sun position at the same latitude but different longitudes may be slightly different. However, it will not affect the Sun path since the Sun only appears earlier or later (within an hour) but following the same locus.

\section{Teaching Experiment}

A teaching experiment has been conducted to evaluate the learning effectiveness of students using traditional teaching aids (the celestial hemisphere, compass, and protractor) and the Sun path observation system. This study randomly selected two classes of 5th-grade students as the experimental samples, one class (28 students) as the control group and the other (28 students) as the experimental group, from an elementary school in northern Taiwan. The control group used traditional teaching aids and the experimental group used the Sun path observation system, respectively (Figure 10). A questionnaire survey was conducted by both groups to investigate the attitudes of students after using different tools for observation.

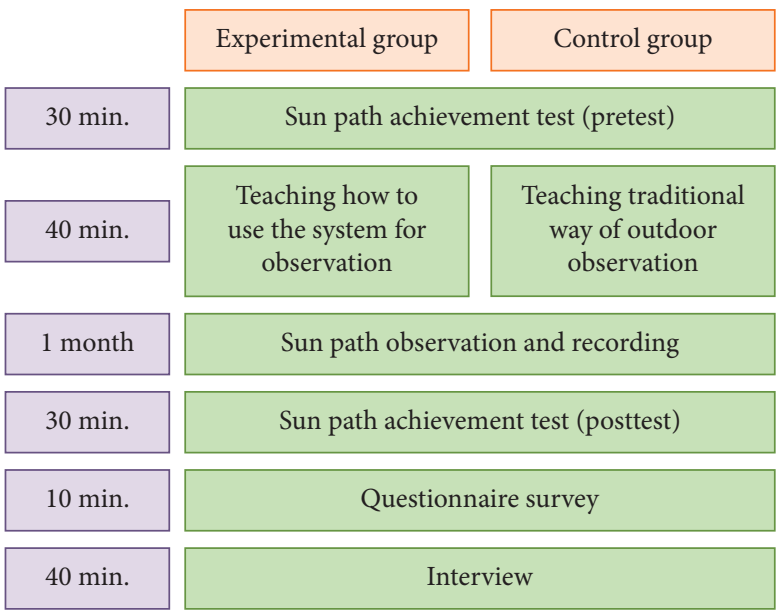

FIGURE 11: The flowchart of teaching experiment.

The achievement test used in this study contains 20 test items which were designed based on the teaching objectives, learning contents, and observation activities. The test items 
TABLE 2: ANCOVA results of learning achievement for both groups.

\begin{tabular}{lcccccc}
\hline & Students & Average & Standard deviation & $f$ & Significance $(p)$ \\
\hline Control group & 28 & 40.18 & 78.75 & 38.57 & 7.77 & \multirow{2}{*}{10.83} \\
Experiment group & 28 & 38.39 & 85.36 & 46.97 & 10.54 & $0.002^{* *}$ \\
\hline
\end{tabular}

${ }^{* *} p<0.01$.

TABLE 3: Questionnaire results of using the teaching tool for the Sun path observation.

\begin{tabular}{|c|c|c|c|}
\hline Question & Experimental group & Control group & Mean difference \\
\hline $\begin{array}{l}\text { (1) I am more interested in learning this subject than I } \\
\text { did before by using the teaching tool }\end{array}$ & 4.36 & 4.00 & $0.36^{*}$ \\
\hline $\begin{array}{l}\text { (2) The teaching tool can help me find out new } \\
\text { problems in learning this subject }\end{array}$ & 3.82 & 3.61 & 0.21 \\
\hline $\begin{array}{l}\text { (3) I would think about the observed phenomena in } \\
\text { a new way by using the teaching tool }\end{array}$ & 4.82 & 3.50 & $1.32^{* * *}$ \\
\hline $\begin{array}{l}\text { (4) I like to use the teaching tool for learning this } \\
\text { subject }\end{array}$ & 4.36 & 3.71 & $0.65^{* * *}$ \\
\hline $\begin{array}{l}\text { (5) I like to use the same way in learning other } \\
\text { subjects }\end{array}$ & 4.21 & 4.18 & 0.03 \\
\hline $\begin{array}{l}\text { (6) I hope there is a chance to learn in this way in the } \\
\text { future }\end{array}$ & 4.89 & 3.68 & $1.21^{* * *}$ \\
\hline $\begin{array}{l}\text { (7) I will recommend the teaching tool to other } \\
\text { students }\end{array}$ & 4.18 & 3.18 & $1.00^{* * *}$ \\
\hline
\end{tabular}

were revised according to the comments of two experts and two science teachers. The questionnaire used in this study is a system satisfaction survey according to the user's experiences after using the teaching tools for learning, and it was designed based on the discussion with experts and science teachers. This study adopted the 5-point Likert scale [20] ( $5=$ strongly agree; $4=$ agree; $3=$ neutral; $2=$ disagree; and $1=$ strongly disagree).

This study adopted a nonequivalent pretest-posttest design to analyze if there is a significant difference in learning effectiveness between the two groups. Before the teaching activities, all students took a pretest on their background knowledge about the Sun path concepts. After conducting the teaching activities, they took the posttest and filled out the questionnaire. The variables of the teaching experiment are listed in Table 1, and the flowchart of the teaching experiment is shown in Figure 11.

In the teaching experiment, an analysis of covariance (ANCOVA) has been conducted to investigate if there is a significant difference in learning effectiveness between the two groups. The statistical software SPSS is used to analyze the test results (Table 2). For the control group, the average scores of pretest and posttest are 40.18 and 78.75 , respectively. For the experimental group, the average scores of pretest and posttest are 38.39 and 85.36 , respectively. The progress made by the experimental group (46.97) is higher than the progress made by the control group (38.57). The power size of the effect is the difference between the average outcomes in two different intervention groups. Cohen's $\mathrm{d}$ is the appropriate effect size measure if two groups have similar standard deviations and are of similar size, and it is calculated as

$$
\text { Cohen's } d=\frac{\left(M_{2}-M_{1}\right)}{\mathrm{SD}}=\frac{(46.97-38.57)}{9.26}=0.91 \text {, }
$$

where $\mathrm{SD}=\sqrt{\left(\mathrm{SD}_{1}^{2}+\mathrm{SD}_{2}^{2}\right) / 2}=\sqrt{\left(7.77^{2}+10.54^{2}\right) / 2}=9.26$.

After excluding the effect of covariance (the background knowledge), the impact of independent variable (the teaching aids) is obtained as $f=10.83$ and $p=0.002<0.01$. A significant difference exists between the control group and the experimental group, and the learning achievement of the latter is higher than that of the former. In other words, the Sun path observation system is more effective than the traditional teaching aids for enhancing the learning achievement of students.

A statistical analysis is conducted on the questionnaire results by the two groups. The average scores in each selected item and their significance are computed for the seven questions to understand the attitudes of students after using the teaching aids to record the Sun path data (Table 3). The questionnaire results show that the experimental group was more satisfied with the tools they used than the control group.

The interview results from the teacher and the experimental group students are summarized in the following to support the validity of the questionnaire results.

(i) Most students considered the Sun path observation system very useful because it can be used to measure the orientation and elevation of the Sun easily without using the compass and protractor.

(ii) The function of automatic recording is helpful, and it can reduce the observation and recording time.

(iii) The functions of setting different observation dates and latitudes are very convenient because the students 
do not have to wait a long time or actually go there to record the Sun path data.

(iv) The function of combining several sets of data to compare the Sun paths in different seasons or at different latitudes can help them understand that the Sun path varies with latitudes and seasons.

(v) The system can be used in the classroom for observing and recording the Sun path to prevent the risk of heatstroke due to staying in the Sun for an extended period of time.

\section{Conclusion}

In this study, a Sun path observation system is developed using the AR technology and the sensor functions on mobile devices to help elementary school students observe and record the Sun path. The system has a built-in celestial model to simulate the Earth's rotation and its revolution around the Sun for calculating the Sun's position in the sky. When holding the mobile device toward the sky, the screen will show the virtual Sun in the same direction as that of the real Sun, and the students can record the Sun orientation and elevation as well as the relative data such as the observation date, time, longitude, and latitude. They can also set different observation times and locations to understand that the Sun path changes with seasons and latitudes.

A teaching experiment has been conducted to analyze the learning effectiveness of students using the Sun path observation system. A questionnaire survey has been conducted to understand the attitudes of students after using traditional teaching aids and the Sun path observation system. The experimental results show that the learning effectiveness of the experimental group is significantly higher than that of the control group. The questionnaire survey and interview results reveal that most students considered the system useful in recording the observation data, and they would recommend it to other students. They thought the system is easy to operate, and they would like to use it if there is a similar requirement in the future.

The system provides situated learning contents about the Sun path concepts, and it converts the observation data into organized and meaningful astronomical knowledge. It is useful for developing the spatial concepts required in learning the relative motion between the Sun and Earth. In addition, the system can solve the problem of being unable to observe the Sun path due to a bad weather or topographical restrictions. Therefore, it is a useful tool for astronomy education in elementary schools.

\section{Conflicts of Interest}

The authors declare that there are no conflicts of interest regarding the publication of this paper.

\section{Acknowledgments}

The authors wish to acknowledge the support by the Ministry of Science and Technology (MOST), Taiwan, under Contract nos. 103-2511-S-007-010-MY2 and 106B2096UB.

\section{References}

[1] J. Dunlop, "How children observe the Universe," Publications of the Astronomical Society of Australia, vol. 17, no. 2, pp. 194-206, 2000.

[2] R. W. Hollingworth and C. McLoughlin, "Developing science students' metacognitive problem solving skills online," Australian Journal of Educational Technology, vol. 17, no. 1, pp. 50-63, 2001.

[3] Kang Hsuan Educational Publishing Group, 2014, https:// www.knsh.com.tw/Index.asp.

[4] K. J. Schoon, "Students' alternative conceptions of Earth and space," Journal of Geological Education, vol. 40, no. 3, pp. 209-214, 1992.

[5] J. Baxter, "Children's understanding of familiar astronomical events," International Journal of Science Education, vol. 11, no. 5, pp. 502-513, 1989.

[6] K. C. Trundle and R. L. Bell, "The use of a computer simulation to promote conceptual change: a quasi-experimental study," Computers and Education, vol. 54, no. 4, pp. 10781088, 2010.

[7] G. J. Hwang and C. C. Tsai, "Research trends in mobile and ubiquitous learning: a review of publications in selected journals from 2001 to 2010," British Journal of Educational Technology, vol. 42, no. 4, pp. E65-E70, 2011.

[8] C.-C. Chen and P.-H. Lin, "Development and evaluation of a context-aware ubiquitous learning environment for astronomy education," Interactive Learning Environments, vol. 24, no. 3, pp. 644-661, 2016.

[9] P. Sommerauer and O. Müller, "Augmented reality in informal learning environments: a field experiment in a mathematics exhibition," Computers and Education, vol. 79, pp. 59-68, 2014.

[10] M. B. Ibáñez, Á. Di Serio, D. Villarán, and C. D. Kloos, "Experimenting with electromagnetism using augmented reality: impact on flow student experience and educational effectiveness," Computers and Education, vol. 71, pp. 1-13, 2014.

[11] T. H. C. Chiang, S. J. H. Yang, and G. J. Hwang, "Students' online interactive patterns in augmented reality-based inquiry activities," Computers and Education, vol. 78, pp. 97-108, 2014.

[12] H. Sollervall, "Collaborative mathematical inquiry with augmented reality," Research and Practice of Technology Enhanced Learning, vol. 7, no. 3, pp. 153-173, 2012.

[13] D. M. Bressler and A. M. Bodzin, "A mixed methods assessment of students' flow experiences during a mobile augmented reality science game," Journal of Computer Assisted Learning, vol. 29, no. 6, pp. 505-517, 2013.

[14] H.-K. Wu, S. W.-Y. Lee, H.-Y. Chang, and J.-C. Liang, "Current status, opportunities and challenges of augmented reality in education," Computers and Education, vol. 62, pp. 41-49, 2013.

[15] H.-Y. Chang, H.-K. Wu, and Y.-S. Hsu, "Integrating a mobile augmented reality activity to contextualize student learning of a socioscientific issue," British Journal of Educational Technology, vol. 44, no. 3, pp. E95-E99, 2013.

[16] N. Drljevic, L. H. Wong, and I. Boticki, "Where does my augmented reality learning experience (ARLE) belong? A student and teacher perspective to positioning ARLEs," IEEE Transactions on Learning Technologies, vol. 10, no. 4, pp. 419-435, 2017.

[17] M. E. C. Santos, A. Chen, T. Taketomi, G. Yamamoto, J. Miyazaki, and H. Kato, "Augmented reality learning 
experiences: survey of prototype design and evaluation," IEEE Transactions on Learning Technologies, vol. 7, no. 1, pp. 38-56, 2014.

[18] W. Tarng, Y.-S. Lin, C.-P. Lin, and K.-L. Ou, "Development of a lunar-phase observation system based on augmented reality and mobile learning technologies," Mobile Information Systems, vol. 2016, Article ID 8352791, 12 pages, 2016.

[19] L. Bot, P.-B. Gossiaux, C.-P. Rauch, and S. Tabiou, "Learning by doing: a teaching method for active learning in scientific graduate education," European Journal of Engineering Education, vol. 30, no. 1, pp. 105-119, 2005.

[20] R. Likert, "A technique for the measurement of attitudes," Archives of Psychology, vol. 22, no. 140, p. 55, 1932. 


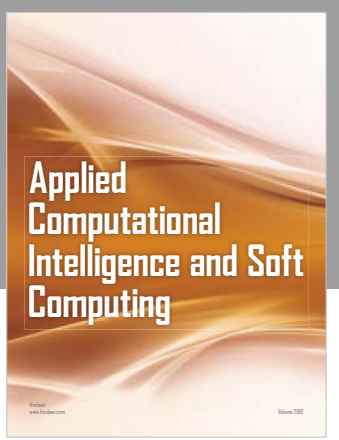

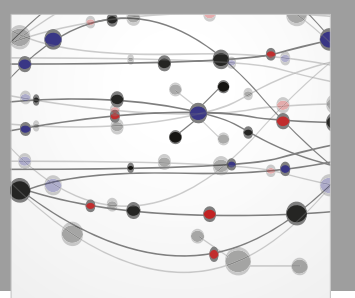

The Scientific World Journal
Submit your manuscripts at

Computing
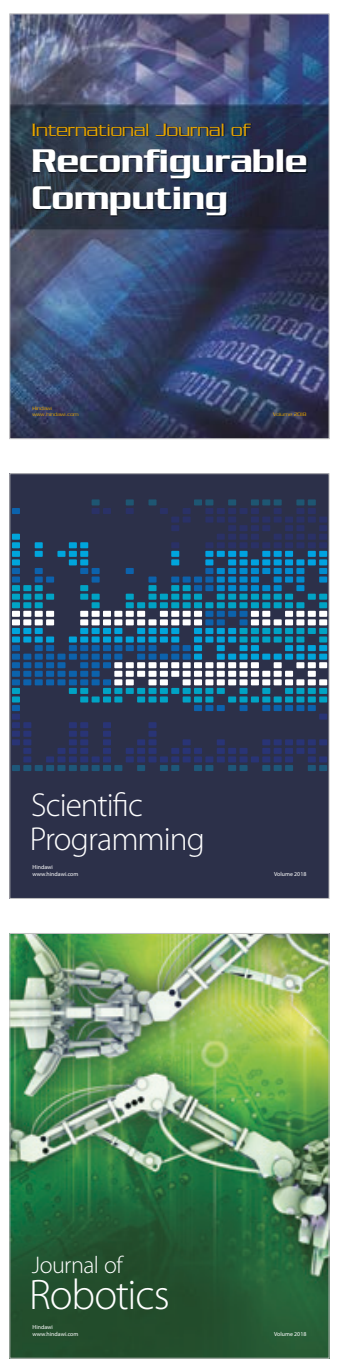

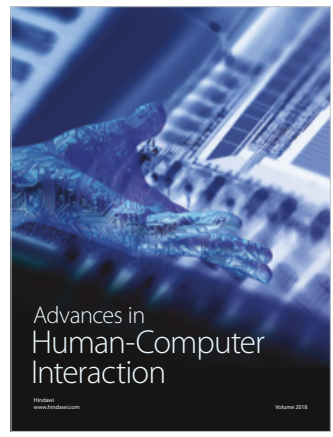

Human-Compute

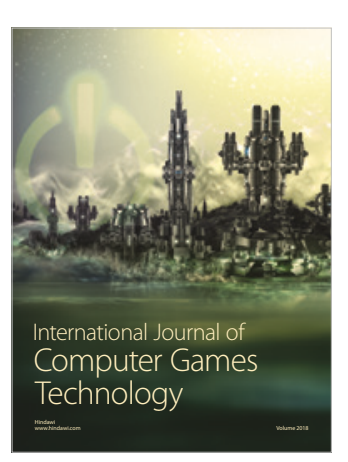

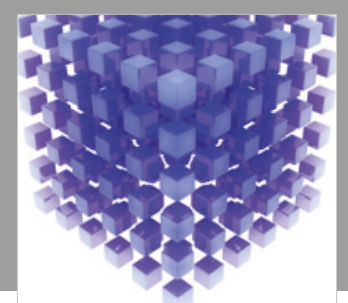

Mathematical Problems in Engineering

\section{Engincering}
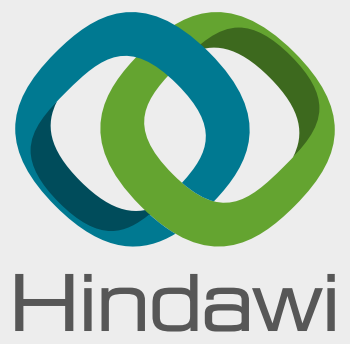

www.hindawi.com
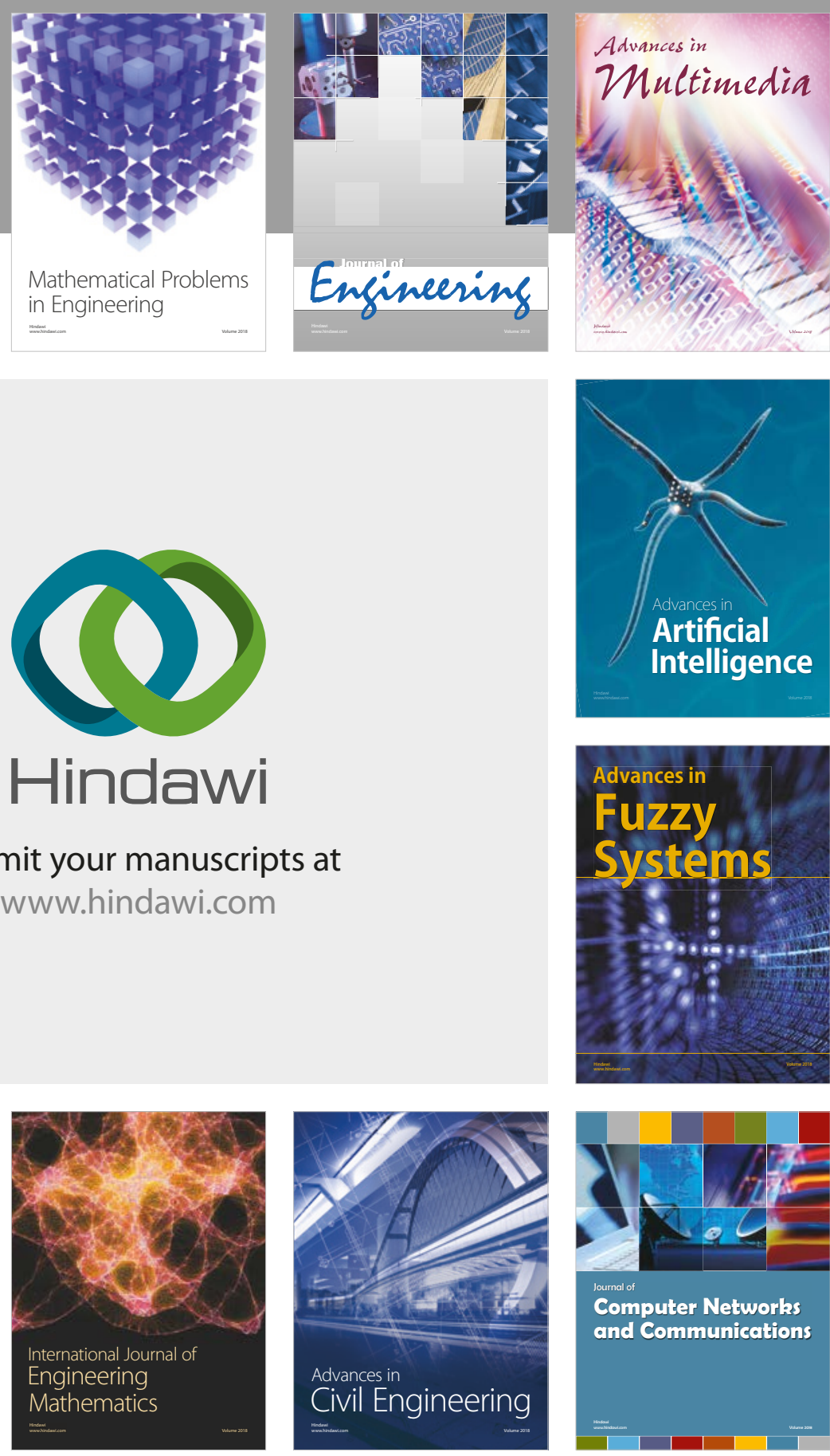

Computer Networks and Communications

Multimedia
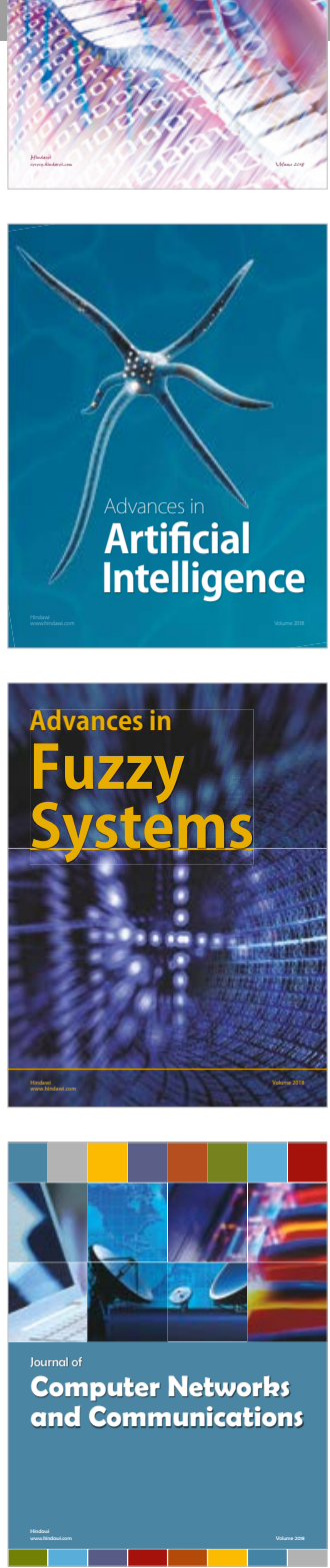

Advances in

Modelling \&

Simulation

in Engineering

interaction

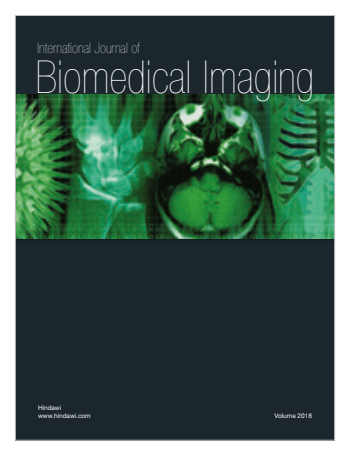

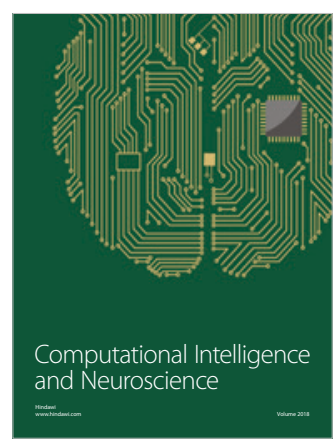

